\title{
Electrical transport in two-phase mixtures
}

\author{
V B TARE \\ Department of Metallurgical Engineering, Institute of Technology, Banaras Hindu \\ University, Varanasi 221005 , India

\begin{abstract}
There is considerable interest in the eloctrical transport in two-phase systems because of their possible technological applications. This paper describes the recent data obtained on the effect of different types of dispersoids on two types of matrixes, viz, NiO, a predominantly p-type semiconductor and AgI, a predominantly ionic conductor. It has been shown that the total electrical conductivities of these composites depend strongly on the nature of the dispersoid as well as the matrix. In both the cases, however, an interfacial region has been shown to play a significant role.
\end{abstract}

Keywords. Electrical conduction; two-phase mixtures; excess enthalpy; interfacial effect.

\section{Introduction}

The traditional approach of calculating the electrical conductivity of two-phase mixtures by taking the weighted average of the bulk conductivity of each phase does not take into account the changes in the charged particles due to the presence of an electrical double layer at the interface between these phases. Wagner (1972) first considered this possibility and postulated that the total electrical conductivity can be markedly affected because of the presence of the interfacial double layer. Subsequent investigations substantiated the deviation from the classical approach in a large number of systems, some of which have found interesting commercial applications. Liang (1973) reported that by the dispersion of $\mathrm{Al}_{2} \mathrm{O}_{3}$ in $\mathrm{Lil}$ the ionic conductivity increased by orders of magnitude. This composite was thus found to be suitable for high current density solid state batteries. In seemingly unrelated experiments Wright et al (1975) reported that the presence of $\mathrm{Al}_{2} \mathrm{O}_{3}$ in the chromia scales found on nickel-chromium alloys markedly reduce the oxidation rates of the alloy.

In spite of these scattered observations and their possible interesting applications, there do not appear to be systematic investigations and satisfactory explanations of the observed behaviour. The present paper summarises the latest contributions on this topic with possible explanations.

Depending upon their conductivity, solids are classified as metals, semiconductors and insulators. Semiconductors are further classified as $n$-type, $p$-type and ionic conductors. Various combinations of dispersoids and matrixes are possible. The examples of dispersion in two typical matrixes are described below, viz.,

(i) dispersion in a semiconducting nickel oxide matrix;

(ii) dispersion in predominantly ionically conducting AgI matrix.

\section{Dispersion in a semiconducting NiO matrix}

$2.1 \mathrm{Ni}_{3} \mathrm{~S}_{2}$ in $\mathrm{NiO}$

Nickel sulphide $\left(\mathrm{Ni}_{3} \mathrm{~S}_{2}\right)$ is known to be a metallic conductor (Yagi and Wagner 1982). Solubility of sulphur in $\mathrm{NiO}$ is reported to be $10^{-2}$ to $10^{-3} \%$ (Pope and Birks 1981). 


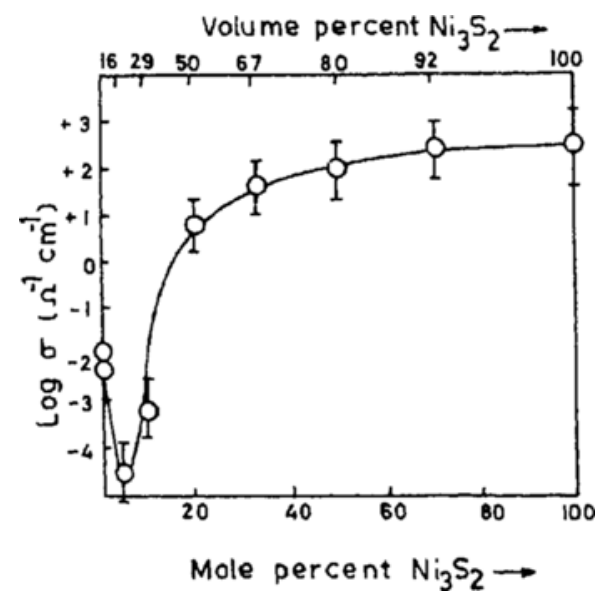

Figure 1. Electrical conductivity as a function of the composition of $\mathrm{NiO}-\mathrm{Ni}_{3} \mathrm{~S}_{2}$ mixtures at $600^{\circ} \mathrm{C}$.

Specific conductivity as a function of $\mathrm{Ni}_{3} \mathrm{~S}_{2}$ concentration is shown in figure 1 at $600^{\circ} \mathrm{C}$. For samples of $\mathrm{NiO}$ heated in sulphur vapour for several days the conductivity is found to decrease only slightly and is also shown in this figure. Significant decrease in conductivity is observed for samples containing $5 \mathrm{~mol} \% \mathrm{Ni}_{3} \mathrm{~S}_{2}$. Above this concentration conductivity again increases with increase in concentration of $\mathrm{Ni}_{3} \mathrm{~S}_{2}$ upto $20 \mathrm{~mol} \% \mathrm{Ni}_{3} \mathrm{~S}_{2}$ above which the variation in conductivity with increase in concentration of $\mathrm{Ni}_{3} \mathrm{~S}_{2}$ is small. Below $20 \% \mathrm{Ni}_{3} \mathrm{~S}_{2}$ in $\mathrm{NiO}$ the composites behave like a semiconductor with predominantly $n$-type conductivity above $5 \% \mathrm{Ni}_{3} \mathrm{~S}_{2}$ and p-type below $5 \% \mathrm{Ni}_{3} \mathrm{~S}_{2}$ in $\mathrm{NiO}$.

The activation energy for conduction estimated from the temperature dependence of conductivity is found to increase with increase in concentration of $\mathrm{Ni}_{3} \mathrm{~S}_{2}$, attain a maximum at $5 \mathrm{~mol} \% \mathrm{Ni}_{3} \mathrm{~S}_{2}$ and then decrease again with the increase in concentration of $\mathrm{Ni}_{3} \mathrm{~S}_{2}$.

Microscopic examination of the composites showed that particle size of $\mathrm{Ni}_{3} \mathrm{~S}_{2}$ varies from 10 to $100 \mu \mathrm{m}$ while that of $\mathrm{NiO}$ is approximately $5 \mu \mathrm{m}$. Above $20 \mathrm{~mol} \% \mathrm{Ni}_{3} \mathrm{~S}_{2}$ the interconnecting network of $\mathrm{Ni}_{3} \mathrm{~S}_{2}$ is clearly observed (Tare and Wagner 1983a).

\section{$2.2 \mathrm{Ni}$ in $\mathrm{NiO}$}

Nickel oxide in equilibrium with $\mathrm{Ni}$ is nearly a stoichiometric compound with very small number of point defects (Tretyakov and Rapp 1969). The electrical conductivity of samples containing varying concentrations of $\mathrm{Ni}$ is shown in figure 2 at $727^{\circ} \mathrm{C}$. Mixtures containing more than $20 \mathrm{~mol} \%$ nickel exhibit very high metallic type conductivity. Mixture containing less than $20 \mathrm{~mol} \% \mathrm{Ni}$, however, behave like semiconductors. The addition of $1 \mathrm{~mol} \% \mathrm{Ni}$ decreases the conductivity. However, on increasing the concentration of $\mathrm{Ni}$ above about $1 \%$, the conductivity also increases (Tare and Wagner 1983b).

The activation energy for conduction for all $\mathrm{Ni}-\mathrm{NiO}$ samples, however, remained the same as that for pure $\mathrm{NiO}$ at $35 \pm 2 \mathrm{k}$ cal. The changeover from predominantly $p$-type 


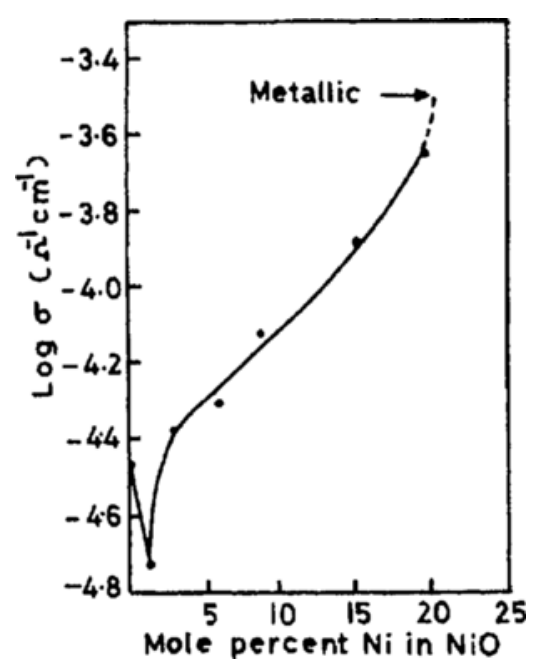

Figure 2. Electrical conductivity as a function of the composition of Ni-NiO mixtures at $727^{\circ} \mathrm{C}$.

conductivity in $\mathrm{NiO}$ occurs to $n$-type at concentrations above about $1 \mathrm{~mol} \% \mathrm{Ni}$. The particle size of both $\mathrm{Ni}$ and $\mathrm{NiO}$ was $5 \mu \mathrm{m}$.

\section{$2.3 \mathrm{CeO}_{2}$ in $\mathrm{NiO}$}

Cerium oxide, although reported to be a predominantly ionic conductor, exhibits n-type conductivity under certain conditions (Tuller and Nowick 1979). NiO is a p-type semiconductor. $\mathrm{CeO}_{2}$ and $\mathrm{NiO}$ have negligible mutual solid solubility. Figure 3 shows the total conductivity of a NiO- $\mathrm{CeO}_{2}$ two-phase system throughout the range of composition at $800^{\circ} \mathrm{C}$. It can be seen that there is a small minimum in the conductivity curve at the $\mathrm{CeO}_{2}$ rich end. For compositions ranging from 20 to $60 \mathrm{~mol} \% \mathrm{NiO}$, the conductivity varies linearly with the composition. However, on either side of these limits the change is small. Similar behaviour was also noted in the variation of activation energy of conduction with composition in the temperature range 600 to $1000^{\circ} \mathrm{C}$. It was difficult to determine the type of current carriers because of the low conductivity particularly for $\mathrm{CeO}_{2}$ rich compositions. NiO rich compositions showed only p-type conductivity (Tare $e$ t al 1985b).

From the data reported above it is clear that when an electron donor phase is added to $\mathrm{NiO}$, a p-type semiconductor, there is initially a decrease in conductivity. Further increase in the concentration of the electron donor phase results in conduction entirely due to the dispersoid. A minimum in conductivity at a fixed composition is thus observed in all the above cases. The concentration at which the maximum is observed is, however, dependent on the nature of the dispersoid and is found to increase with the decrease in electron concentration available for conduction in the dispersoid.

The initial decrease in conductivity is considered to be due to the trapping of holes at the interfaces due to the space charge layer. The number of mobile holes available for conduction thus decreases, resulting in a decrease in total conductivity. After all the 


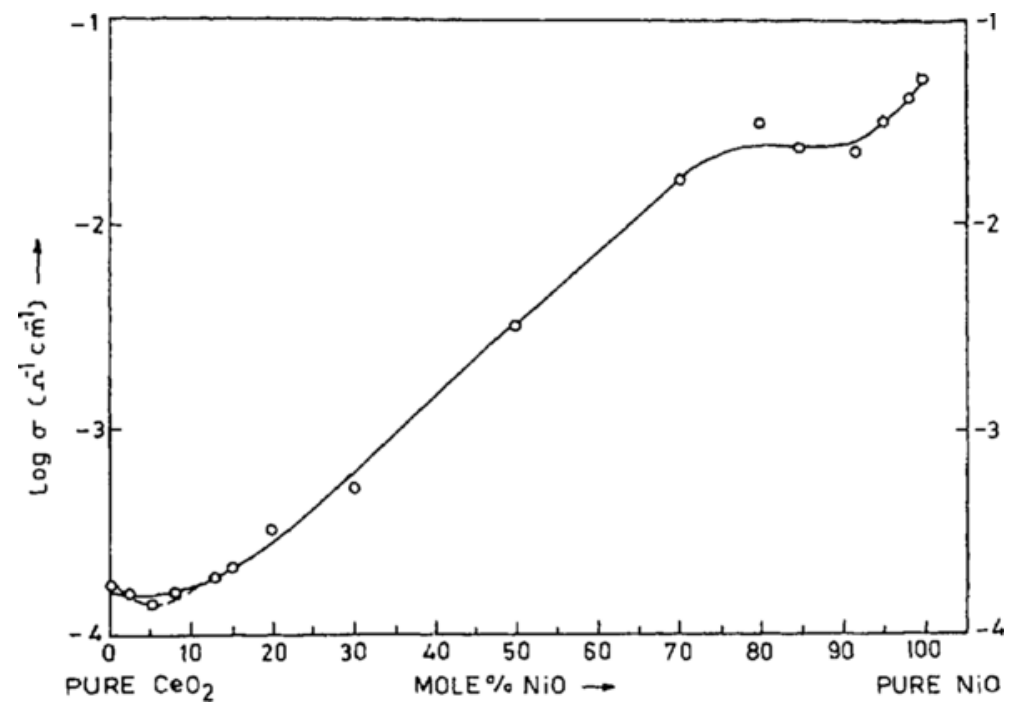

Figure 3. Eloctrical conductivity as a function of the composition of $\mathrm{CeO}_{2}-\mathrm{NiO}$ mixtures at $800^{\circ} \mathrm{C}$.

available holes are thus trapped, further conduction is only due to the mobile electrons drawn from the dispersoid. The larger the number of electrons available from the dispersoid, the smaller the concentration required to trap all the available holes from the matrix.

The role of electrons from the dispersoid phase contributing to the total conduction has been discussed by Wagner (1972), who postulated that the inclusion of metal or metallically conducting particles provide clouds of excess electrons surrounding the individual inclusions as space charge layers. Accordingly the expression for the number of electrons in the medium between two metallic particles with radius $r_{1}$ and at distance $2 r_{2}$ between the dispersoid particles is given by

$$
n_{2}=\left(1 \cdot 1 g \cdot f^{1 / 3} \varepsilon k T\right) /\left(4 \pi r_{2}^{2} e^{2}\right)
$$

where $f$ is the volume fraction of the dispersoid, $\varepsilon$ the dielectric constant, $g$ depends upon the ratio of number of electrons at the surface of the dispersoid to the number in the matrix and is $\approx 20$. If the concentration of electrons available for conduction in the matrix is too small the overall conductivity is determined by the electrons from the dispersoid. Thus

$$
\sigma=(22 \varepsilon k T u / 4 \pi e) \cdot\left(f / r_{1}^{2}\right)
$$

Therefore at constant temperature and for constant values of $r_{1}$ when $r_{1} \ll r_{2}$, the conductivity is directly proportional to the volume fraction of the dispersoid.

The data obtained for dispersion of nickel particles in nickel oxide can be used to verify this (figure 4). For the dispersion of $\mathrm{CeO}_{2}$ and $\mathrm{Ni}_{3} \mathrm{~S}_{2}$ this relationship could not be verified because of the limited data available, large variations in particle size and several other considerations. 


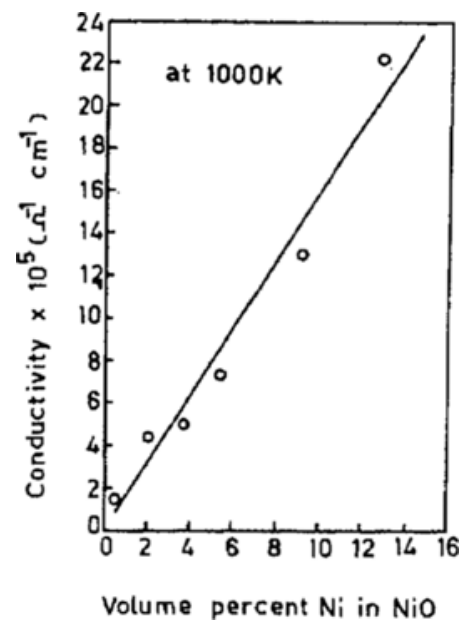

Figure 4. Electrical conductivity as a function of the volume fraction of nickel in $\mathrm{NiO}$ at $727^{\circ} \mathrm{C}$

\section{Dispersion in predominantly ionically conducting AgI matrix}

\section{$3.1 \mathrm{Al}_{2} \mathrm{O}_{3}$ in $\mathrm{AgI}$}

Aluminium oxide, $\mathrm{Al}_{2} \mathrm{O}_{3}$ is an insulator. The effect of the dispersion of several types of insulating particles on the conductivity of AgI-insulator composites has been investigated by Shahi and Wagner (1981). All types of insulating particles were found to increase the conductivity whereas according to the conventional approach the conductivity is expected to decrease. The effect of insulating particles of $\mathbf{A l}_{2} \mathrm{O}_{3}$ as the dispersoid in an AgI matrix have been investigated in greater detail. Figure 5 shows the change in conductivity of the $\mathrm{AgI}-\mathrm{Al}_{2} \mathrm{O}_{3}$ composite as a function of temperature and concentrations of $\mathrm{Al}_{2} \mathrm{O}_{3}$ in the temperature range 25 to $200^{\circ} \mathrm{C}$. Figure 6 shows the change in conductivity as a function of concentration of $\mathrm{Al}_{2} \mathrm{O}_{3}$ at $25^{\circ} \mathrm{C}$ for $\beta \mathrm{AgI}$ and at $200^{\circ} \mathrm{C}$ for $\alpha \mathrm{AgI}$. Whereas the conductivity is found to decrease with increase in concentration of $\mathrm{Al}_{2} \mathrm{O}_{3}$ in $\alpha \mathrm{AgI}$, considerable enhancement in conduction is observed in $\beta \mathrm{AgI}$. Another interesting observation is the occurrence of pseudo-hysteresis for the $\beta \rightarrow \alpha$ transformation. A typical feature of this hysteresis is that while the transformation temperature during the increasing temperature cycle i.e. for $\beta \rightarrow \alpha$, remains fairly same, the temperatue of $\alpha \rightarrow \beta$ transformation during cooling deviates from true transformation temperature. Figure 7 shows that the deviation $\Delta T$ varies linearly with the increase in the concentration of the dispersoid. The enhancement of conductivity and the extent of hysteresis depend only on the surface area (figure 8). Thus for larger particle size, the concentration of the dispersoid needed to achieve the same effect is also higher (Chowdhury et al 1985).

\section{$3.2 \mathrm{AgBr}$ in $\mathrm{AgI}$}

Silver bromide and silver iodide are both predominantly ionic conductors. The solubility of $\mathrm{AgBr}$ in $\mathrm{AgI}$ is about $10-15 \mathrm{~mol} \%$ while that of $\mathrm{AgI}$ in $\mathrm{AgBr}$ is 


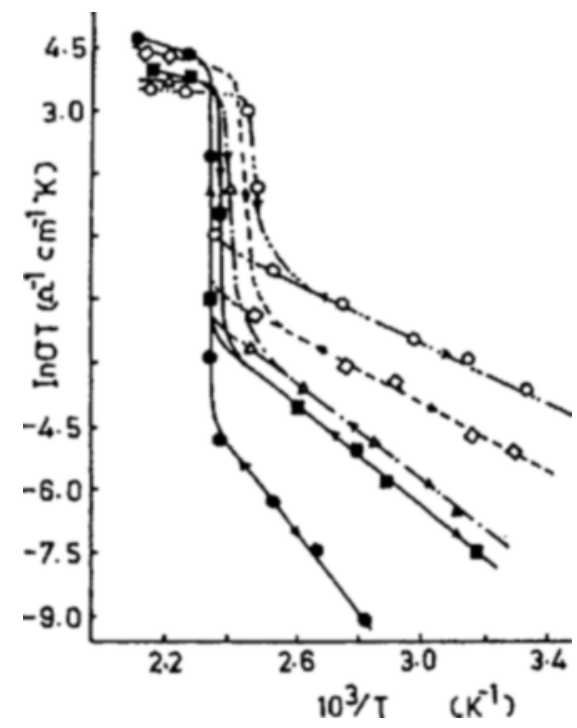

Figure 5. Electrical conductivity as a function of the temperature at various concentrations of $\mathrm{Al}_{2} \mathrm{O}_{3}$ in $\mathrm{AgI}$ [closed circles-AgI; closod squares-AgI $+10 \mathrm{~mol} \% \mathrm{Al}_{2} \mathrm{O}_{3}(0.3 \mu \mathrm{m})$; open triangles- $\mathrm{AgI}+20 \mathrm{~mol} \% \mathrm{Al}_{2} \mathrm{O}_{3}(0-3 \mu \mathrm{m})$; open squares-AgI $+10 \mathrm{~mol} \% \mathrm{Al}_{2} \mathrm{O}_{3}(0-06 \mu \mathrm{m})$; open circles $\left.-\mathrm{AgI}+20 \mathrm{~mol} \% \mathrm{Al}_{2} \mathrm{O}_{3}(0.06 \mu \mathrm{m})\right]$.

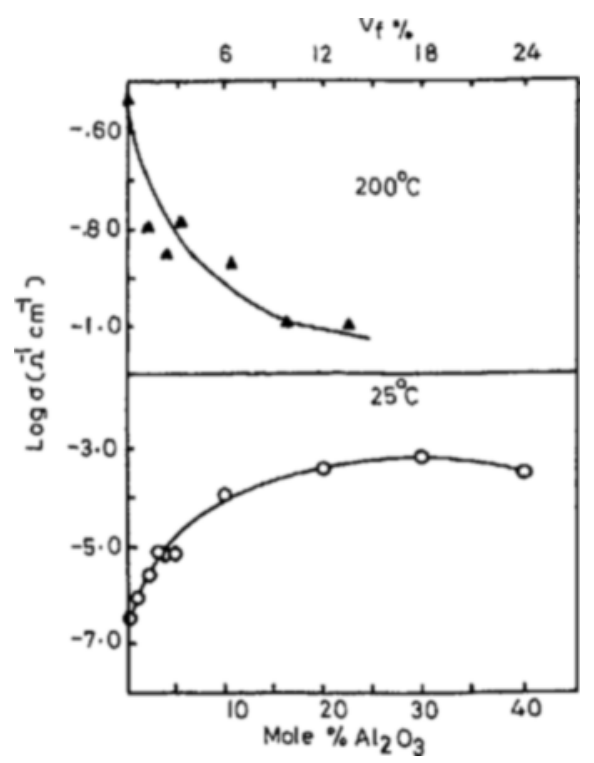

Figure 6. Electrical conductivity as a function of the mole and volume percent of $\mathrm{Al}_{2} \mathrm{O}_{3}$ $(0-06 \mu \mathrm{m})$.

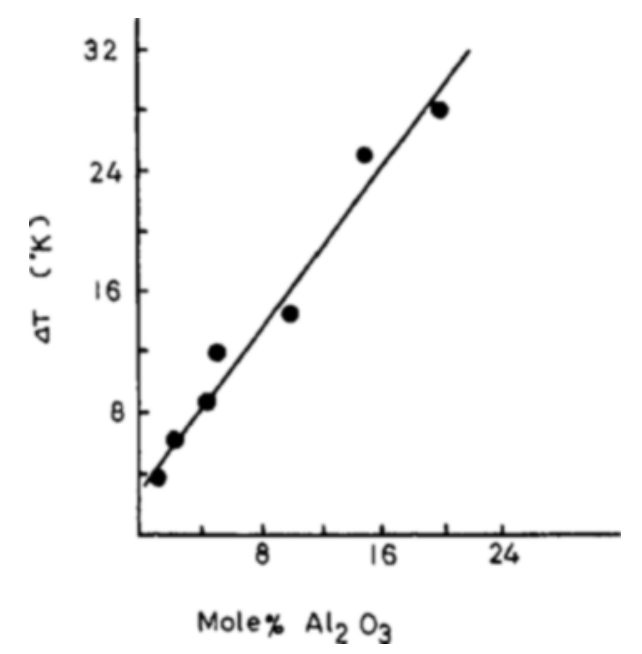

Figure 7. $\Delta \mathrm{T}$ as a function of the mole $\% \mathrm{Al}_{2} \mathrm{O}_{3}(0-06 \mu \mathrm{m})$.

approximately $30 \mathrm{~mol} \%$ at $25^{\circ} \mathrm{C}$ (Shahi and Wagner 1981). For compositions between these solubility limits there is a two-phase region. The conductivity throughout the range of AgI-AgBr composition has been investigated by Shahi and Wagner (1981) and is shown in figure 9. It is clear that, instead of having a linear variation of conductivity in the two-phase region, a maximum in conductivity is observed at around $25 \mathrm{~mol} \%$ 
Electrical transport in two-phase mixtures

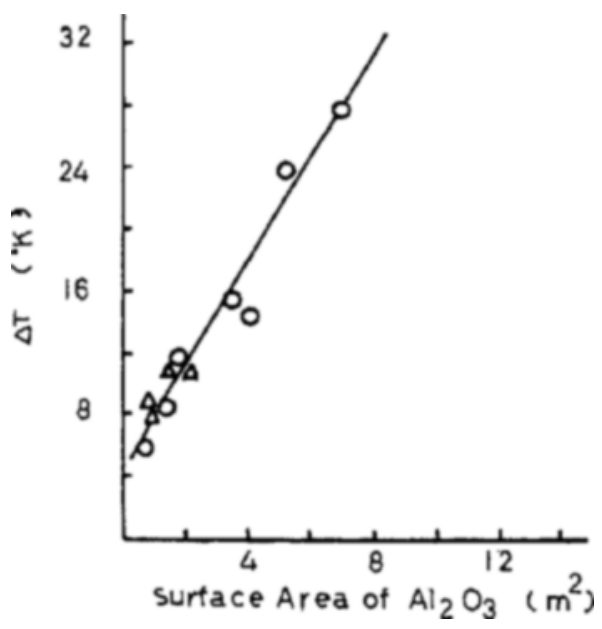

Figure 8. $\Delta \mathrm{T}$ as a function of the surface area of $\mathrm{Al}_{2} \mathrm{O}_{3}$ per gram of $\mathrm{AgI}$ [circles $-\mathrm{Al}_{2} \mathrm{O}_{3}$ $(0-06 \mu \mathrm{m}) ;$ triangles $\left.-\mathrm{Al}_{2} \mathrm{O}_{3}(0-3 \mu \mathrm{m})\right]$.

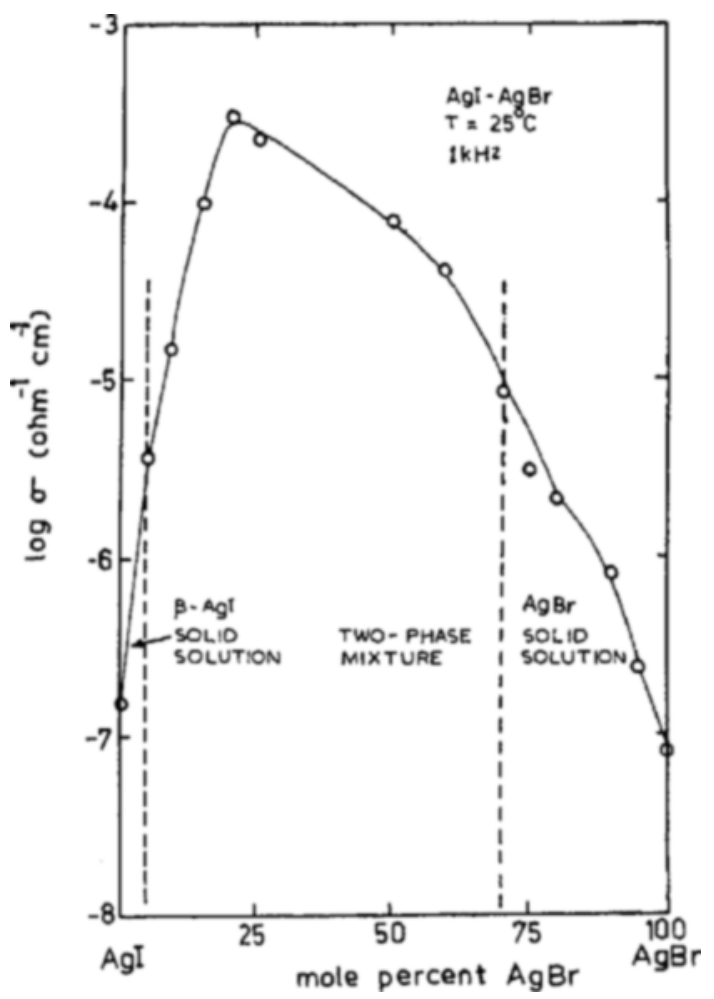

Figure 9. Electrical conduction as a function of the composition of AgI-AgBr mixtures at $25^{\circ} \mathrm{C}$. 
$\mathrm{AgBr}$ in $\mathrm{AgI}$. Both $\mathrm{AgI}$ and $\mathrm{AgBr}$ are predominantly ionic conductors having Frenkel disorder. The conductivity is essentially due to the migration of silver ion interstitials or silver ion vacancies. The enhancement in conduction indicates the creation of additional defects. The experimental evidence for the generation of additions defects has been recently obtained by precise calorimetric measurements (Khandkar et al 1984). It has been shown that there is a finite difference in enthalpy content (excess enthalpy) between the molten and the mechanically mixed two-phase mixtures of the two end compositions in the AgI-AgBr system. Figure 10 shows that this enthalpy difference is maximum at equimolar end compositions. The densities of the end compositions are not very different. Hence, this composition is also the composition of maximum interfacial area.

Occurrence of maxima in excess enthalpy at compositions which generate maximum surface area indicates that additional defects are created at the interface and that the excess enthalpy is due to the formation of these additional defects.

Pack (1979) postulated that the total conductivity in a two-phase mixture consists of three parts, viz., (i) that due to the matrix, (ii) that due to the interfacial layer, and (iii) that due to the dispersoid. Thus

$$
\sigma_{\text {total }}=\sigma_{1}\left(1-V_{v}\right)+G \cdot S \cdot\left(1-V_{v}\right)^{2}+\sigma_{2} \cdot V_{v},
$$

where

$\sigma_{1}=$ conductivity of the matrix material;

$\sigma_{2}=$ conductivity of the dispersoid material;

$V_{v}=$ volume fraction of the dispersoid;

$S=$ surface area created by dispersoid per unit volume of the mixture;

$G=$ factor accounting for the excess charges per unit volume of the mixture.

Thus, the excess conductivity is considered to be due to the presence of an interfacial layer.

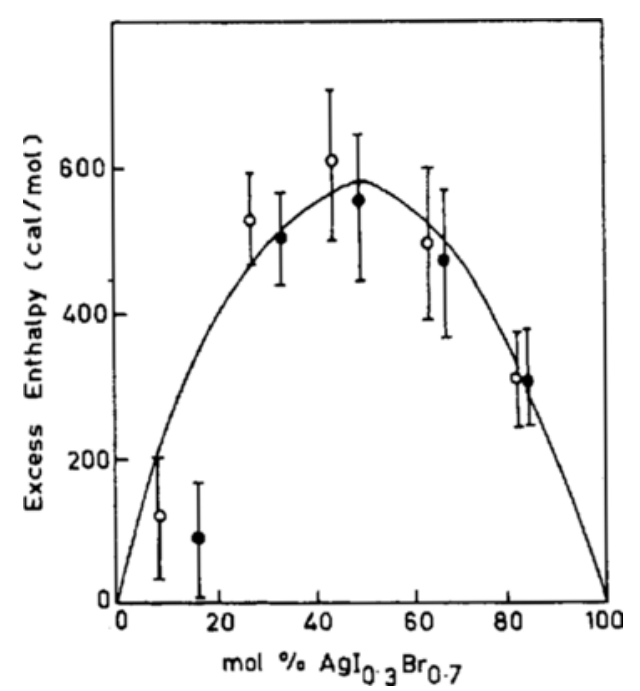

Figure 10. Excess enthalpy $\left(H_{518}-H_{298}\right)_{\text {melted }}-\left(H_{518}-H_{298}\right)_{\text {unmeled }}$ as a function of $\mathrm{AgI}_{0.3} \mathrm{Br}_{0.7}$ in $\mathrm{AgL}_{0.9} \mathrm{Br}_{0.1}(\mathrm{O})$ and $\mathrm{AgI}_{0.85} \mathrm{Br}_{0.15}(\mathrm{O})$. 
The generation of defects at the interface is schematically shown in figure 11. If we assume $\lambda$ as the Debye length, the maximum number of defects are created in this region. Thus a highly conducting region surrounds a despersoid and hence the overall increase in conductivity is expected. Occurrence of maxima at different compositions for conductivity and excess enthalpy is probably due to the fact that whereas conductivity depends upon mobility as well as the number of migrating species, the excess enthalpy depends upon the number only (Khandkar et al 1984).

It is difficult to visualise the exact nature and type of the defects created at the interface. However, data obtained on $\mathrm{AgI}-\mathrm{Al}_{2} \mathrm{O}_{3}$ composites suggests that the dispersion of $\mathrm{Al}_{2} \mathrm{O}_{3}$ in $\mathrm{AgI}$ is associated with additional cation vacancies at the $\mathrm{AgI} / \mathrm{Al}_{2} \mathrm{O}_{3}$ interface for both $\alpha$ - and $\beta$-AgI. At high temperatures $\alpha$ - $\mathrm{AgI}$ has the socalled average structure in which all silver ions are moving in between relatively immobile iodine ions in a $b c c$ arrangement. Silver ion mobility in this phase is so high that equilibrium between various defects is easily attained. Consequently, when $\mathrm{Al}_{2} \mathrm{O}_{3}$ is introduced into $\alpha-\mathrm{AgI}$, the cation vacancies generated at the interface act as sinks for some of the mobile silver ions and the conductivity decreases. Since a critical concentration of silver ion interstitials is needed for the $\alpha \rightarrow \beta$ transition, this transition is delayed.

At lower temperatures in which $\beta$-AgI is stable, the equilibrium between defects is not easily achieved. Thus in this case the total conductivity is due to the highly conducting interfacial layer because of the creation of a large number of vacancies in addition to the contribution from each of the two phases present. Since the transition temperature depends on the number of defects in the bulk $\mathrm{AgI}$ which is not altered, the transition temperature remains unaffected by the presence of $\mathrm{Al}_{2} \mathrm{O}_{3}$ as the dispersoid.

\section{Conclusions}

It is thus clear from the above discussion that the region at the interface between two different phases plays an importani role in influencing the total conductivity of a twophase system. The contribution of the interfacial region depends upon the nature of the

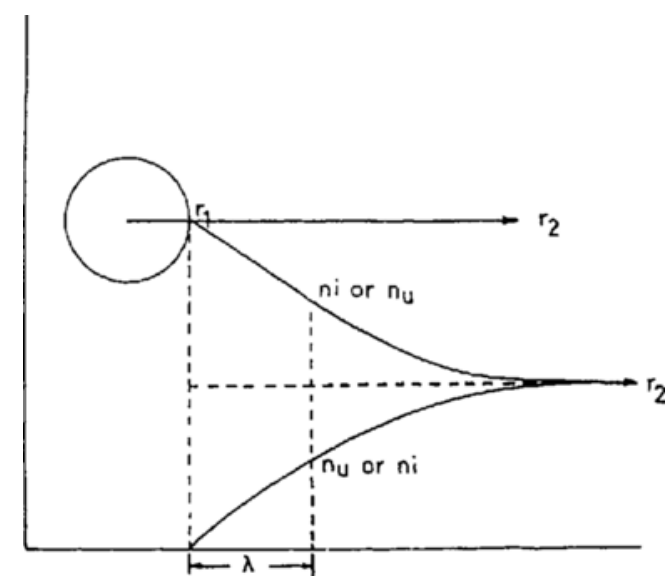

Figure 11. Schematic representation of the formation of defects at the interfacial region. 
dispersoid as well the matrix. Much more systematic data is needed to formulate a generalised model.

Occurrence of two phases in a variety of situations is more the rule than the exception. For example, in corrosion of metals and alloys in mixed gaseous environment the corrosion product often consists of more than one phase. Since, in a situation when a compact mechanically perfect and adherent corrosion product is formed, the kinetics of corrosion strongly depends upon the transport properties of such a product layer, investigations of the type described in this paper become important. It may be possible to influence the rate of corrosion by monitoring the amount of the second phase in the corrosion product.

Besides this, considerable enhancement of conduction in ionic compounds, because of the presence of appropriate second phases, has an obvious potential for technological applications.

\section{References}

Chowdhury P, Tare V B and Wagner J B Jr 1985 J. Electrochem. Soc. 132123

Khandkar A, Tare V B, Navrotsky A and Wagner J B Jr 1984 J. Electrachem. S $\propto c .1312683$

Liang C $1973 \mathrm{~J}$. Electrochem. Soc. 1201289

Pack S 1979 Paper presented at the Eloctrochemical Society Meeting, Los Angeles, October

Pope M C and Briks N 1981 Oxid. Met. 12191

Shahi K and Wagner J B Jr 1981 J. Electrochem. Soc. 1286

Tare V B and Wagner J B Jr 1983a J. Phys. Chem. 54292

Tare V B and Wagner J B Jr 1983b J. Phys. Chem. 546459

Tare V B, Mehrotra G M and Wagner J B Jr 1985 Paper presented at the fifth International Conference on Solid State Ionies, Lake Tahoe, Aug. 18-24

Tretyakov Y and Rapp R A 1969 Trans. Metall. Soc. AIME 2451235

Tuller H L and Nowick A S 1979 J. Electrochem. Soc. 126299

Yagi $\mathrm{H}$ and Wagner J B Jr 1980 Oxid. Met. 11

Wagner C 1972 J. Phys. Chem. Solids 331091

Wright I G, Wicox B A and Jaffee 1975 Oxid. Met. 9275 